\title{
MEASUREMENT AND COMPARISON OF CONTROL ROD WORTH OF BTRR USING INHOUR EQUATION AND PERIOD REACTIVITY CONVERSION TABLE
}

\author{
MD. IQBAL HOSAN, M. A. M. SONER ${ }^{1}$, MD. FAZLUL HUQ ${ }^{1 *}$ AND KHORSHED \\ AHMAD KABIR
}

Department of Nuclear Engineering, University of Dhaka, Dhaka-1000, Bangladesh

\begin{abstract}
In a nuclear reactor, control rod is a very essential part and plays the elementary role in the reactor control during reactor start up, normal power operation, experimental research and shutdown. To perform all these operations safely, knowledge of differential and integral worth of the control rod is mandatory. In this study, the differential and integral worth curve of all control rods of BAEC TRIGA Research Reactor (BTRR) have been determined by using the positive period method. Reactor period was measured from 1.5 folding time, doubling time, 5 folding time respectively; and in the above three cases reactivity has also been calculated from INHOUR equation and period reactivity conversion table. The total worth of all control rods of BTRR are measured as 14.888 \$, 14.672 \$, 14.348 \$ from INHOUR equation and 13.978 \$, 13.672 \$, 13.357 $\$$ from period reactivity conversion table for 1.5 folding time, doubling time and 5 folding time respectively. The measured reactivity has also been compared with the previously measured reactivity and due to fuel burn up of the reactor expected lower values were observed.
\end{abstract}

Key words: BTRR, Control rod reactivity, INHOUR equation, Positive period method, Doubling time

\section{Introduction}

The reactivity of the control rod is one of the important parameters for management of reactor operation, and used for the prediction of control rod position at start-up and the estimation of the core excess reactivity during the reactor operation [M.A. Salam et al., 2014b]. Control rod worth offers greater safety in reactor operation and aids the task of reactivity management. Periodic measurement of reactivity worth of control rods is one of the licensing requirements for any nuclear reactor. Many countries however, already developed their own reactivity measurement system [S.A. Ansari, 1991; S.E. Binney and Bakir, 1989].

The reactivity depends on its chemical composition, location of the control rod, fuel burn up and the surrounding material. Reactivities and reactivity increments play an important role

*Corresponding author: <fazlul.huq@du.ac.bd>.

${ }^{1}$ Center for Research Reactor (CRR), Atomic Energy Research Establishment (AERE), Bangladesh Atomic Energy Commission (BAEC). 
in reactor physics, safety, control and operational schedules [Tombakoglu and Cecen, 2001]. Reactor control rod reactivity measurement is necessary to assure the performance of control rods. A variety of experimental techniques have been developed to measure control rod worth. Such methods can be classified as either static or dynamic measurement techniques. Amongst them the positive period method, the doubling time method and the rod-drop method are most popular dynamic methods. The positive period method is commonly utilized for positive reactivity measurement [Duderstadt and Hamilton, 2005].

The objective of this research is to investigate the reactivity of all control rods of the BTRR by the positive period method for 1.5 folding time, doubling time and 5 folding time. These three measurements have been done at the same time for getting more reliable data. Within these three measurements only 1.5 folding time for INHOUR equation is used previously whereas, in this research, doubling time and 5 folding time are used for both INHOUR equation and period reactivity conversion table. This gives approximately same results and these results are compared with that of previously measured data and the design safety parameters of the reactor. The result which we have found by investigation can serves as a guideline for the research reactor operators and users. It can also be used for the validation of the computer code of the research reactor.

\section{BRIEF DESCRIPTION OF THE BTRR}

The BTRR (BAEC TRIGA Research Reactor) is the only nuclear reactor in the country. The reactor has been designed and constructed by the General Atomics (GA) of USA [A. Zahed Chowdhury et al., 2013]. The reactor has been used for manpower training, radioisotope production and various $R \& D$ activities in the field of Neutron Activation Analysis (NAA), Neutron Radiography (NR), and Neutron Scattering (NS) etc. The BTRR reactor has six control rods designated as Transient, Shim-1, Shim-2, Shim-3, Shim-4 and Regulating [M.A. Salam et al., 2014a].

The BTRR is a pool type, light water cooled, graphite reflected reactor; designed for steady state and square wave operation up to a power level of $3 \mathrm{MW}$ (thermal) and can also be pulsed up to a peak power of about $852 \mathrm{MW}$ with a maximum reactivity insertion of up to $\$ 2.00$ having a half-maximum pulse width of nearly 18.6 milliseconds. BTRR fuel is a solid homogeneous mixture of Er-U-ZrH alloy containing about $20 \%$ weight of uranium enriched to about $19.7 \%$ U-235 and about $0.47 \%$ weight of erbium. The burnable poison Erbium in the U-Zr matrix contributes to the long core lifetime for the TRIGA reactors. The hydrogen-to-zirconium atom ratio of the fuel-moderator material is about 1.6 to 1 [BAEC, 2013].

The important safety feature of BTRR is the Prompt Negative Temperature Coefficient of Reactivity (PNTCR). The nominal value of PNTCR for the BTRR is about 
$1.07 \times 10^{-4} \% \Delta \mathrm{k} / \mathrm{k} /{ }^{\circ} \mathrm{C}[\mathrm{GA}, 1986]$. Because of this characteristic of fuel, reactor can safely be operated in pulse mode. The reactor core consists of 100 fuel elements ( 93 standard fuel elements, 5 Fuel Follower Control Rods (FFCR) and 2 instrumented fuel elements), 6 control rods (5 FFCR and 1 air follower control rod), 18 graphite elements, 1 Dry Central Thimble (DCT), 1 pneumatic transfer system irradiation terminus and $1 \mathrm{Am}-\mathrm{Be}$ neutron source. Fig. 1 shows the core configuration of the reactor. All these elements are placed and supported in-between two $55.25 \mathrm{~cm}$ diameter grid plates and arranged in a hexagonal lattice. Two Instrumented Fuel Elements (IFEs) in the core measure the fuel temperature during reactor operation.

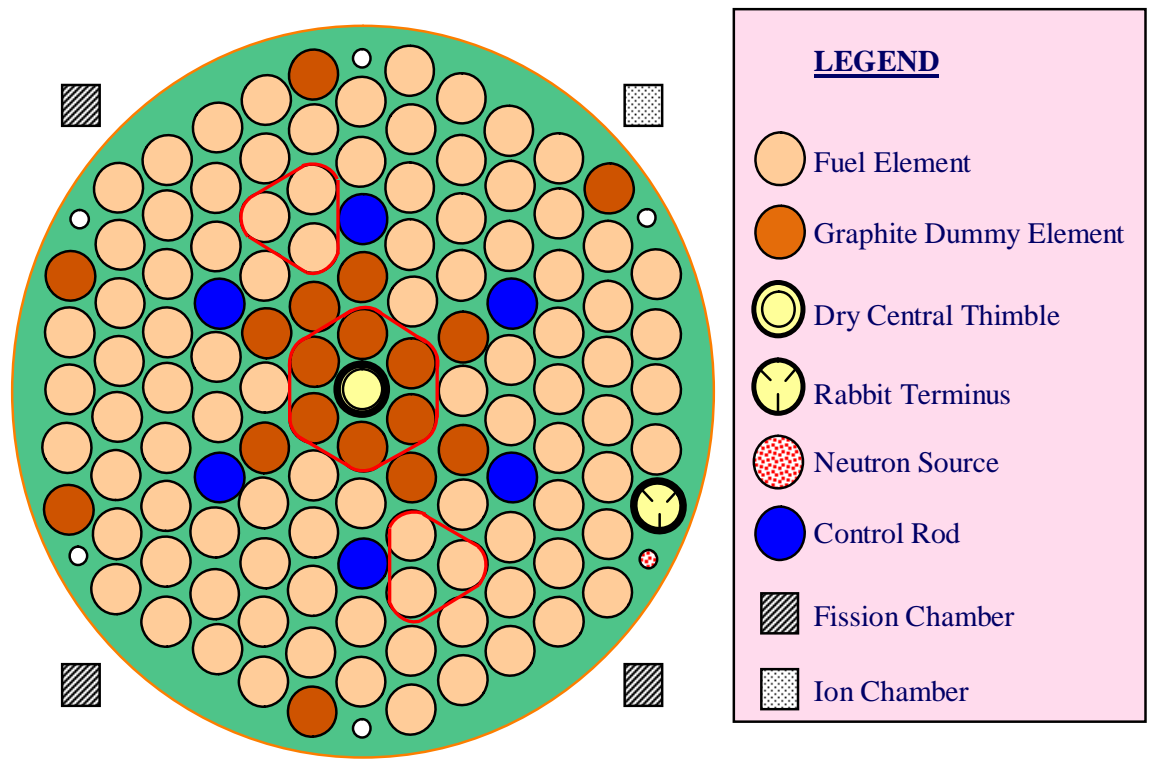

Fig. 1. Core configuration of the reactor

\section{EXPERIMENTAL PROCEDURE}

Reactor control rod worth has been measured by the positive period method using digital instrumentation \& control (I\&C) system of the BTRR. Prior to the measurement of the control rod reactivity, the reactor was kept shutdown for about 4 days to ensure Xenon free environment within the reactor core.

In this method, the range switch was set at AUTO; the reactor was made critical at $50 \mathrm{~W}$, by raising \& banking all control rods except the test rod which is fully inserted in the core, so that the temperature increase during the experiment is negligible. The neutron source is removed from the core and placed it in the storage rack in the reactor tank. The test rod has been withdrawn from the known critical positions through small distances 
and the positions are recorded. This adds a positive reactivity to the system so that the reactor is slightly supercritical and the power will increase exponentially with time. Then, the 1.5 folding time, doubling time and the 5 folding time has been determined by using stopwatch. After taking reading the other control rods except the test rod were adjusted to make the reactor critical at $50 \mathrm{~W}$ again. The procedure is repeated until the test rod has been calibrated along its whole length.

Following equation is used to calculate the reactor period $(\mathrm{T})$ for each withdrawal of the 1.5 folding time, doubling time and the 5 folding time [Shaw, 1969].

$$
P(t)=P_{0} e^{\frac{t}{T}}
$$

Where $\mathrm{P}(\mathrm{t})$ is the reactor power at time $\mathrm{t}$ and $\mathrm{P}_{0}$ is the initial power level prior to rod withdrawal.

This reactor period $(T)$ is used to calculate the reactivity $(\rho)$ in dollar by using the following INHOUR equation,

$$
\rho(\$)=\frac{1}{\beta e f f}\left[\frac{1}{\left(1+\frac{1}{T}\right)}\left\{\frac{1}{T}+\sum_{i=1}^{6} \frac{\beta_{i}}{1+\lambda_{i} T}\right\}\right]
$$

Where, $l$ is the prompt neutron generation time and the summation term applies to the delayed neutron group effects, $\lambda_{i}$ is the decay constant for the $\mathrm{i}^{\text {th }}$ delayed neutron group and $\beta_{i}$ is the fraction of the delayed neutrons is the $\mathrm{i}^{\text {th }}$ group and $\beta_{\text {eff }}$ is the effective delayed neutrons fraction (the $\beta_{\text {eff }}$ of the BTRR reactor is 0.007 ).

The reactivity $(\rho)$ in dollar was also calculated from period reactivity comparison table using the above calculated reactor period $(\mathrm{T})$.

\section{RESULTS AND DISCUSSION}

A curve of reactivity $(\rho)$ vs. rod position was drawn to get the differential rod worth curve. The preceding value of reactivity $(\rho)$ was added with successive reactivity $(\rho)$ and a curve reactivity $(\rho)$ vs. rod position was plotted to get the integral rod worth curve for each of the period measured. The differential rod reactivity and the integral rod reactivity curves of transient rod and shim-4 rod using INHOUR equation and period reactivity table are compared in Figs. 2-5. 


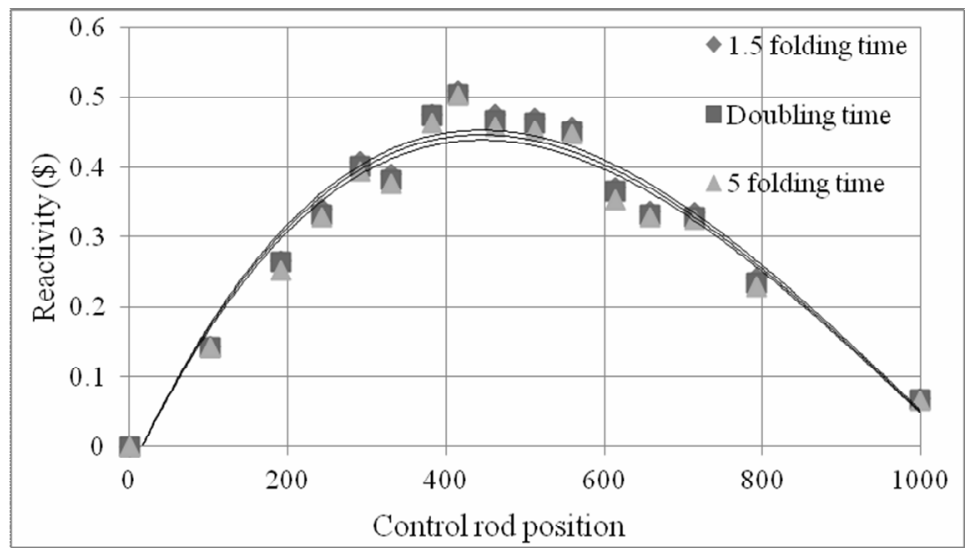

Fig. 2 Shim-4 rod differential curve for INHOUR equation.

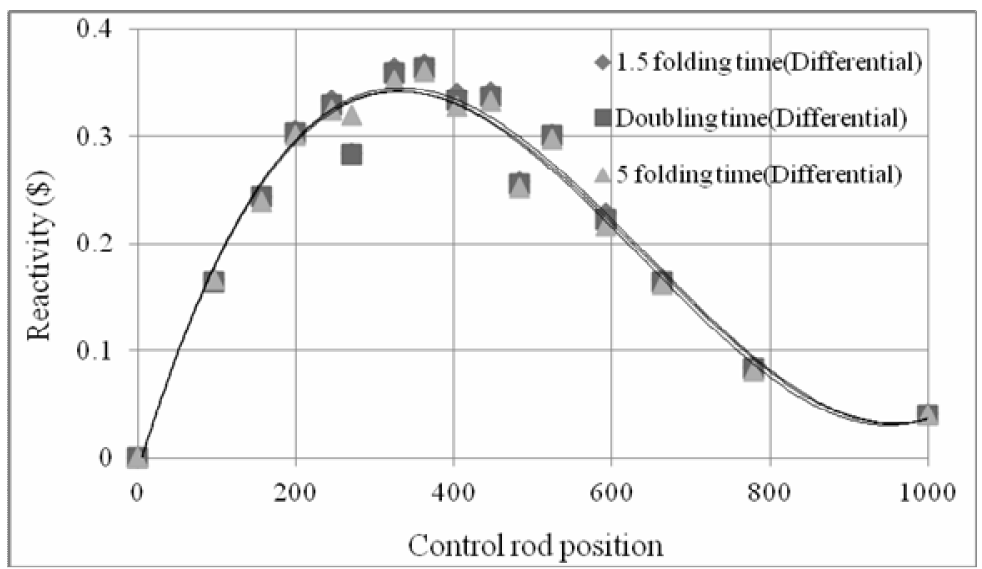

Fig. 3 Transient rod differential curve for INHOUR equation.

As shown in Fig. 2 and Fig. 3 the differential curve conforms to axial flux shape. In general, it is cosine shaped, peaking at mid core and minimum at the top and bottom of the core. Any point on the curve represents the amount of reactivity that one unit of rod motion from corresponding position of control rod would insert in the core [Reed Robert Burn, 1988].

At the bottom of the core, where there are few neutrons, rod movement has little effect so the change in rod worth per unit varies a little. As the rod approaches the center of the core its effect becomes greater, and the change in rod worth per unit change is greater. At the center of the core the differential rod worth is greatest and varies little with rod motion. As the rod move from the center to the top of the core, the rod worth per unit change again decreased due to lesser flux density in upper region [Reed Robert Burn, 1988; Rose et al., 2011]. 


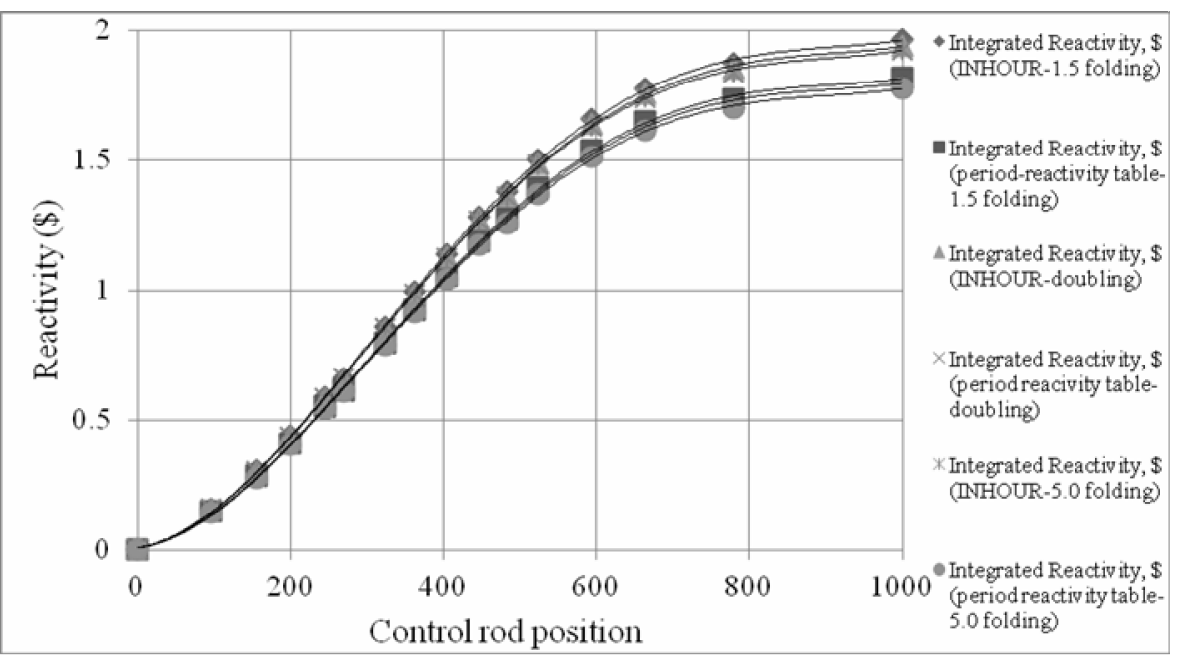

Fig. 4. Integral rod worth curve for transient rod.

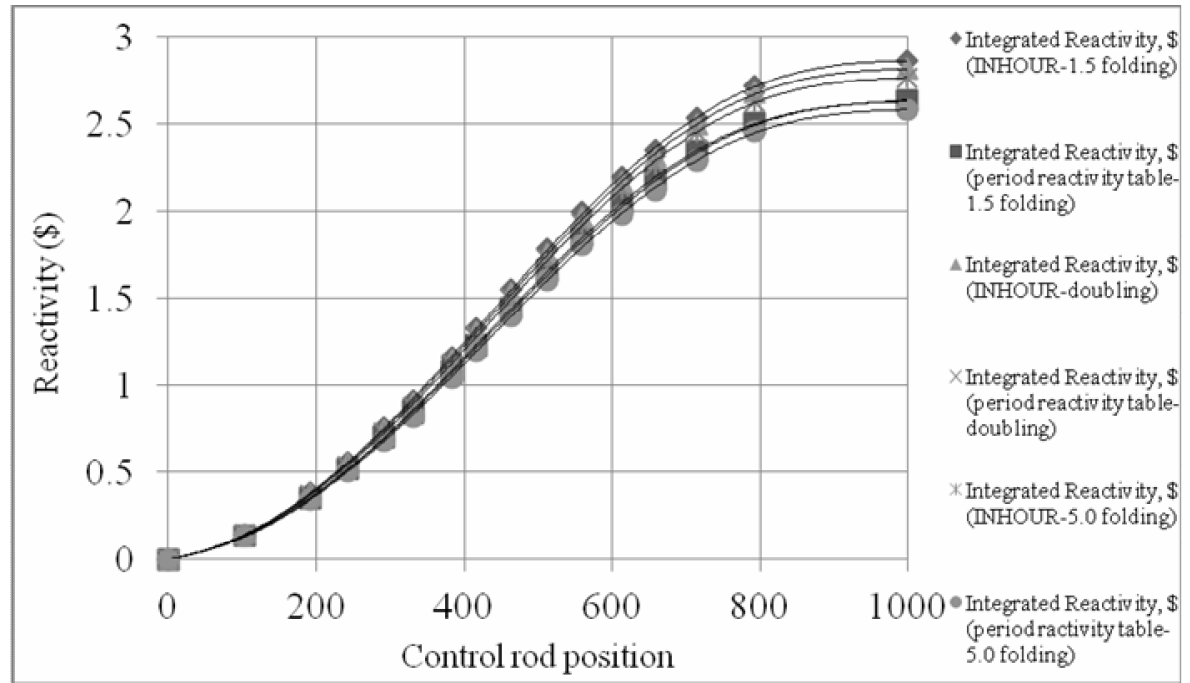

Fig. 5. Integral rod worth curve for shim-4.

The Integral rod worth curve was found approximately "S" shape that was expected [M.A. Salam et al., 2014a; Reed Robert Burn, 1988]. Fig. 4 and Fig. 5 show that, the slope of the curve and therefore the amount of reactivity inserted per unit of withdrawal are greatest when the control rod is midway out of the core. This occurs because the area of greatest neutron flux is near the center of the core; therefore, the amount of change in neutron absorption is greatest in this region [DOE, 1993]. It is also observed that the reactivity of the control rod increases slowly at lower and upper part of the control rod 
compare to the middle position of the rod. If the slope of the curve for integral rod worth in Fig. 4 and Fig. 5 is taken, the result is a value for rate of change of control rod worth as a function of control rod position.

From Fig. 2 to Fig. 5, it is evident that the reactivity curves (both for differential and integral) drawn from data achieved by three different methods are of similar trend.

The differential and integral curves of other four rods has also been determined and found the same trend as with curves for previous two rods.

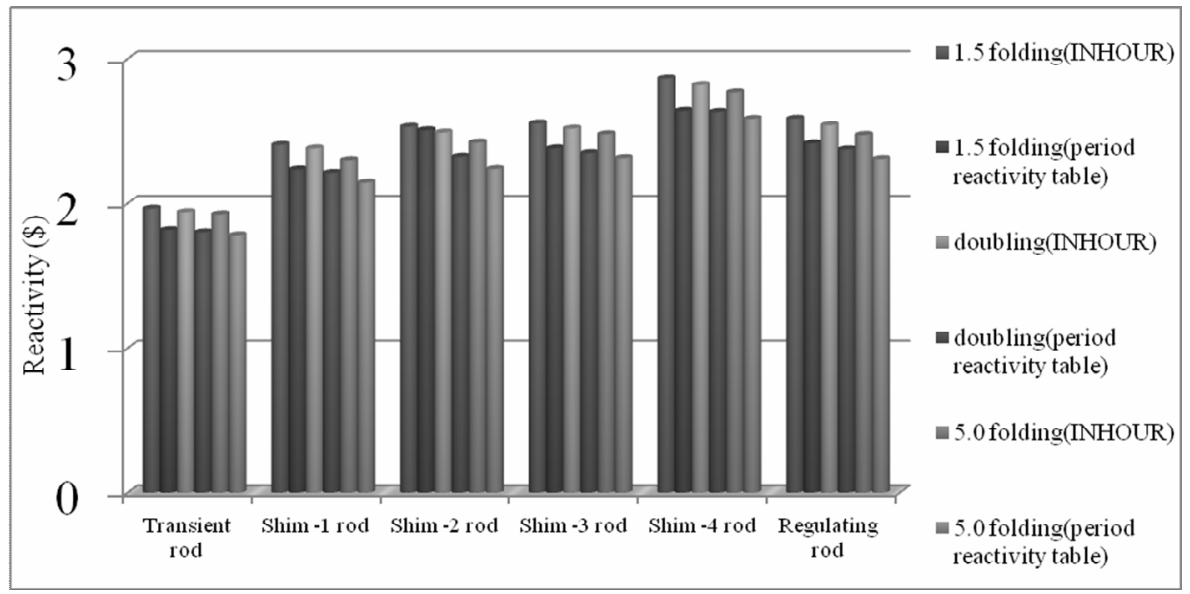

Fig. 6. Individual reactivity change.

Fig. 6 represents the variation of reactivity of each control rod for INHOUR equation and period reactivity table measurement. The variation between the INHOUR equation and period reactivity table reactivity worth are $0.91 \$$ for 1.5 folding, $1.0 \$$ for doubling time, $0.99 \$$ for 5 folding time.

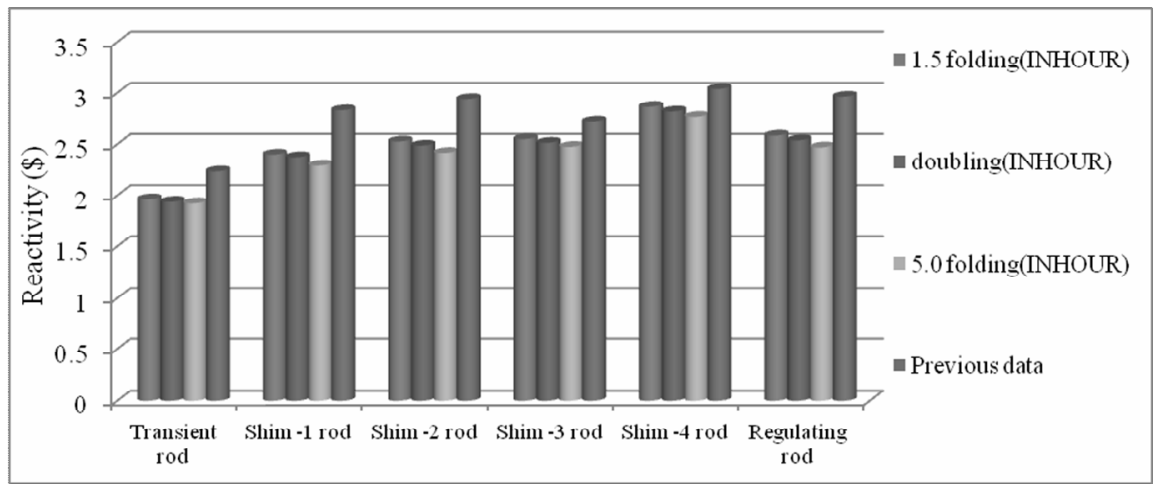

Fig. 7. Individual reactivity change with previous data (2013)

The total reactivity of all control rods are determined as $14.888 \$$ for 1.5 folding time, $14.672 \$$ for doubling time, 14.348 \$ for 5 folding time and average is $14.636 \$$ 
using INHOUR equation and $13.978 \$$ for 1.5 folding time, $13.672 \$$ for doubling time, $13.357 \$$ for 5 folding time and average is $13.669 \$$ using period reactivity table in June 6 , 2014. In 2013, the total reactivity worth was measured 16.732 \$ [M.A. Salam et al., 2014a]. The present reactivity of CRs is decreased by $2.096 \$$ for INHOUR equation and $3.063 \$$ for period reactivity table as shown in Fig. 7. The current worth is smaller than the previous worth because in the previous measurement the fuel burn up was $700 \mathrm{MWds}$ and current burn up is $760 \mathrm{MWds}$. Fig. 8 represents the total reactivity of all control rods for investigated and previous data [M.A. Salam et al., 2014a].

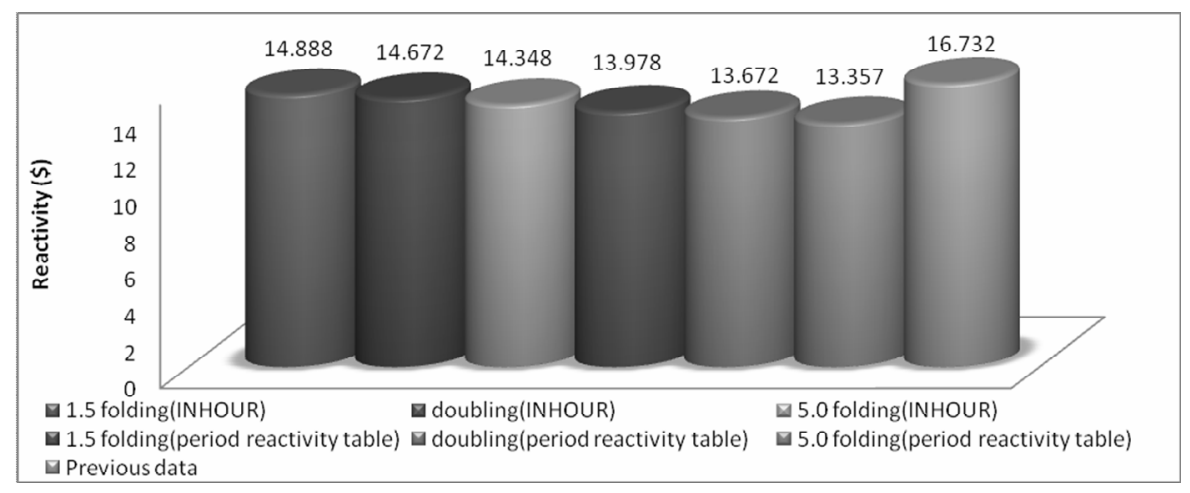

Fig. 8. Total reactivity change.

\section{CONCLUSION}

Control rod worth is the main concern to ensure operational safety of the reactor. This paper represents the maximum reactivity of the control rods which is obtained from the 1.5 folding measurement and the minimum reactivity of the control rods which is obtained from the 5 folding time measurement. The difference between the INHOUR equation reactivity and period reactivity conversion table reactivity is about $5 \%$ in all the three cases. The present reactivity of the control rods decreases from the previously measured reactivity of the control rods and it will decrease continuously in future because of core burn up. The obtained differential curves are not exactly symmetrical about the midpoint of the rod and integral curve are not purely " $\mathrm{S}$ " shape. This is due to the neutron flux distribution in the BTRR core. From the analysis of these results obtained in this research it was concluded that the control rod worth is enough to shut down the reactor safely.

\section{ACKNOWLEDGEMENTS}

The authors are thankful to Engr. Md. Abdus Salam, Chief Engineer and Director, ROMU, BAEC for his guidance and constant encouragement to investigate the safety issues of the reactor. The authors are also thankful to all the teachers of Department of 
Nuclear Engineering, University of Dhaka for their constant support and inspiration throughout the work. Finally, the authors express their thanks to the ROMU operational staff for their cooperation in the research works.

\section{REFERENCES}

"Annual report of the reactor operation and maintenance unit". Atomic Energy research Establishment, Bangladesh Atomic Energy Commission, July 2013.

Ansari, S. A. 1991. Development of on-Line Reactivity Meter for Nuclear Reactors. Nuclear Science, IEEE Transac-tions, 38(4): 946-952.

Binneyand, S. E., A. J. M. Bakir. 1989. Design and Development of a Personal-Computer-Based Reactivity Meter for a Research Reactor. Nuclear Technology, 85: 97331-105902.

Burn, Reed Robert. 1988. Introduction to Nuclear Reactor Operations. Detroit Edison Company, University of Michigan.

DOE Fundamentals Handbook Nuclear physics and Reactor theory volume 2 of 2, doe-hdbk1019/2-93 January 1993.

Duderstadt, J. J. and L. J. Hamilton. 2005. Nuclear Reactor Analysis. John Wiley \& Sons, New York, p. 268.

General Atomics (GA), Safety Analysis Report of BAEC 3MW TRIGA Mark-II Research Reactor, 1986.

Gomes do Prado Souza, Rose Mary and Amir Zacarias Mesquita. 2011. Experimental determination of neutronic parameters in the IPR-R1 TRIGA reactor core, 2011 International Nuclear Atlantic Conference - INAC 2011.

Salam, M. A., M. A. M. Soner, M. A. Sarder, A. Haque, M. M. Uddin, M.M Sarker, S. M. A. Islam. 2014a. Measurement of control rod reactivity and shutdown margin of 3 MW TRIGA Mark-II research reactor using analogue and digital I\&C system. Annals of Nuclear Energy 68: $257-261$

Salam, M. A., M. A. M. Soner, M. A. Sarder, A. Haque, M. M. Uddin and A. Rahaman, 2014b. Measurement of neutronic safety parameters of the 3 MW TRIGA Mark-II research reactor. Progess in Nuclear Energy 74: 160-165.

Shaw, J. 1969. Reactor Operation, International ed. Pergamon Press Ltd.

Tombakoglu, M. and Cecen, Y. 2001. Control rod worth evaluation of TRIGA Mark-II reactor. In: Proceedings of the Nuclear Energy in Central Europe, Portoroz, Slovenia.

Zahed Chowdhury, A., M. A. Zulquarnain, A. Kalam, A. Rahman, M. A. Salam, M. A. Sarder, M. R. I. Khondoker and M. M. Rahman. 2013. Beam Port Leakage Problem in the BAEC TRIGA Mark-II Research Reactor and the Corrective Measures Implemented. International Journal of Scientific \& Engineering Research, 4(4): 79-381. 